\title{
Quality of care in developing countries: relevance and reality
}

In countries where basic health needs are not met and where economic and health indicators highlight urgent priorities for public health measures, should concerns about quality of health care have any place and how is British experience relevant to healthcare quality in developing countries?

Countries in economic and social transition face the dual problems of substantial mortality and morbidity from vector borne diseases such as malaria and chagas as well as infectious diseases, but also an increasing incidence of cancer and coronary heart disease as urbanisation and economic development change lifestyles and create their own health risks. The health sector in many developing countries is often rudimentary and disjointed with poor referral systems being ill equipped to cope with high demands for health care. ${ }^{1}$ Such systems often lack comprehensive or appropriate infrastructure for both primary and acute care and coverage in rural and urban areas is uneven; basic equipment is often unequally distributed and all but essential drugs, antiseptics, and anaesthetics, may be missing. In this situation, human resources can be cheap, but training beyond basic clinical skills is not widely available. Salaries for clinical staff are low and morale among doctors and nurses sinks as competition for jobs is high and numbers of trainees for medical and nursing posts are poorly regulated; people feel insecure in short term contracts working in underresourced services.

Imposing external or internal approaches for monitoring quality into such an unstable and complex system seems like the final insult for staff working against all odds, especially when many of the methods used in the United Kingdom, United States, and other developed countries are unproved in their ability to discern good from bad quality care and are often costly. Yet governments and health professionals in developing countries are keen to explore quality issues, seeing them as a central dimension of health sector reform.

Suspending my incredulity on recent visits to Peru and Bolivia, a rationale for concerns about quality became apparent. Quality of health care is not about the unidimensional interaction between a health professional and patient. It is about proper management of organisations, cultural values, and building an integrated approach to providing access to care among front line staff agreeing appropriateness and deciding on standards for effective delivery of services. Under these circumstances, differences between the United Kingdom and the developing world become a question of scale. We are clearly pursing the same issues: the difficulty of making change, the preoccupation when implementing quality measures with concepts and ideas, and the difficulty of taking the practical steps.

In the United Kingdom, clinical audit was made real through the employment of audit officers in hospital and community health services and of facilitators by Medical Audit Advisory Groups in primary care. Evaluation has been equivocal about the value of this approach as the concept underlying improvements in quality relies on local ownership and personal professional responsibility within an organisation. ${ }^{2}$ Overreliance on audit officers may have had the effect of interposing external assessment on what should be a profoundly intrinsic and internal process; it may not be the key to developing integral quality systems.

A more rational impetus has been given to healthcare quality in the United Kingdom by the development of the clinical effectiveness initiative which sets out a scientific process for examining the quality of care. With this approach gold standards for quality assurance are derived from a systematic review of research evidence and applied to local experience. Clinical effectiveness can be secured when knowledge from research evidence is applied to the process of care with the aim of achieving desired outcomes. Applying similar rigor to healthcare policy issues on access and appropriateness of healthcare interventions is of equal importance. Measures can be developed to assess the extent to which resources are being directed to target populations - those in greatest need of health care, those most likely to benefit from specific interventions, those with no access to alternative sources of health care-and extended to monitoring the value and usefulness of programmes of health care. Are they investing resources for elderly people in a way which balances the achievement of health from prevention and treatment? Will increasing the availability of care for newborn infants-say for the treatment of chagas disease-offer a more efficient deployment of resources than increasing the number of antenatal visits available to low income families?

Taking the broadest possible view of quality in health care, monitoring is clearly of major significance to developing countries and to programmes for health sector reform. Suspicion about the quality of care together with cultural barriers impeding the use of formal health services contrive to reduce uptake of care among the poorest communities. The Bolivian population for example, is multicultural and plurilingual; a census undertaken in 1992-3 suggested that almost $75 \%$ of the population was indigenous distributed over 37 different ethnic groups of which Quechuas and Aymaras are the largest and the most usual languages spoken. National level health indicators show alarmingly low levels of health and wellbeing and growing disparities between the rural and urban populations ${ }^{2}$ which may well be exacerbated by the growing urbanisation of the population. At an overall level of 395/100 000 maternal mortality for Bolivia is already the second highest in the whole of Latin America and the Caribbean yet regional data suggest that mortalities in the rural areas, particularly in the altiplano, could be up to $127 \%$ higher than the national average. Likewise, infant mortality in the rural area of Potosi reached 123/1000 live births whereas the national average is around $75 / 1000$ live births.

Much of the population in Bolivia has no or little access to health care; estimates from the World Health Organisation suggest that $33 \%$ of the total population$22 \%$ in the urban areas and $48 \%$ in rural areas-have no formal access to health care. ${ }^{4}$ Yet, even where services are available low attendance rates are a common experience for health posts and health clinics in both rural and urban areas. Access to health care is clearly not a simple matter of the availability of health services. Impoverished communities and particularly indigenous communities are less likely to use public health services, even where they have geographical access and services are free, than people in the social health insurance system (premiums are paid through employment) or those able to afford the private sector. Although this may be due to cultural barriers and the use of informal or other sources of health care such as local pharmacies or the jateri or witch doctors, quality of care and concern about the attitude of health professionals is also reported as underlying poor uptake of services among those likely to be most in need. 
Solutions to the problem of access - such as the involvement of local advocates within clinics-or well targeted educational programmes for specific groups within the local communities being considered may improve uptake of services provided local people are able to develop a deeper confidence in the capacity of services to meet their health needs adequately.

Against the new agenda for poverty reduction, set out by the government as a priority for investment in aid programmes to the developing world, resources might well be targeted towards exporting systems for clinical quality providing these consider the need for a balance between access and health care. Selecting appropriateness and access as key criteria for quality monitoring offers a means for integrating public health policy priorities into emerging systems for health care. Avoiding the service environment led by supply and demand that now characterises much of the developed world ought to be a priority for health policy which recognises the link between broader social and environmental factors and ill health-and the limitation of the formal process of health services whatever the quality.

ALISON FRATER

Assistant Director of Public Health,

West Hertfordshire Health Authority

1 Groenewegen, Peter P, Calnan M. Changes in the control of health care systems in Europe. European fournal of Public Health 1995;5:240-4.

2 Walshe K, Coles J. Medical audit: in need of evaluation. Quality in Health Care 1993;2:189-90.

3 Bolivia - Encuesta Nacional de Demografia y Salud 1994. La Paz, Bolivia: Instituto Nacional de Estadistica, Macro International, October 1994

4 Necesidades y Expectativas de Cooperacion Internacional en Salud en el Nivel Nacional. La Paz, Bolivia: Departmental y Municipal, May 1997. 